\title{
Retinoblastoma cT3 TNM Finding v7
}

National Cancer Institute

\section{Source}

National Cancer Institute. Retinoblastoma CT3 TNM Finding v7. NCI Thesaurus. Code C88761.

Severe intraocular disease. (from AJCC 7th Ed.) 